\begin{tabular}{c} 
journal homepage: http://ijiemjournal.uns.ac.rs/ \\
International Journal of Industrial \\
Engineering and Management \\
Volume $11 / \mathrm{No} 1 /$ March $2020 / \mathrm{pp} 3-18$ \\
\hline
\end{tabular}

Original research article

\title{
Criticality evaluation to support maintenance management of manufacturing systems
}

\author{
I.S. Lopes *, M.C. Figueiredo, V. Sá \\ ALGORITMI Centre, Department of Production and Systems, University of Minho, \\ Campus of Azurém, 4800-058 Guimarães, Portugal
}

\begin{abstract}
A B STR A C T
This paper focuses on criticality evaluation for supporting daily equipment maintenance management and the definition of medium and long-term maintenance actions to improve equipment and, therefore, productivity. These two different purposes led to the development of two different methods for criticality evaluation, using criteria adjusted for each case. The first method is based on rules for defining priorities for corrective and preventive maintenance tasks. Since a failure mode of critical equipment is not necessarily critical, priorities for maintenance tasks are assigned to tasks rather than to equipment. The second method uses Analytic Hierarchy Process to prioritize equipment based on its performance. This method is based on the indicators commonly monitored by maintenance departments. In addition to assessing equipment performance, it considers the maintenance effort made to achieve the evaluated performance. The selection of the criticality criteria and the development of the methods was based on literature review and triggered by a case study in a multinational automotive company. With the integration of the proposed methods in a computerized maintenance management system, maintenance technicians and managers are able to know in real time the tasks that should be performed first and to monitor the overall performance of equipment in the plant, focusing improvements where they are more required.
\end{abstract}

ARTICLE INFO

Article history:

Received June 13, 2019

Revised October 25, 2019

Accepted October 30, 2019

Published online November 13, 2019

Keywords:

Criticality evaluation;

Equipment classification;

Equipment prioritization;

Maintenance management;

Performance ranking

*Corresponding author:

Isabel Lopes

ilopes@dps.uminho.pt

\section{Introduction}

The maintenance function has become more important for manufacturing companies due to the need of increasing efficiency and effectiveness to achieve demanding and competitive goals [1]. Nowadays, many industries are producing 24 hours a day and, therefore, machines are pushed to their limits to deal with this demand. This increase in machines utilization leads to an increase in maintenance demand to retain or restore machines to a state they are able to operate at the required performance [2]. According to Xiao et al. [3], the objectives of the companies are more easily achieved if machine unavailability is minimized and failure probability is reduced. Periodic maintenance, also called time-based maintenance (TBM), can be effective in reducing failure frequency and the scheduling of this preventive maintenance is a necessary activity in maintenance engineering [4].

Maintenance departments that have to manage several requests for preventive or corrective actions need to define priorities for tasks and equipment in order to reduce the negative impact of breakdowns in production systems. Since resources are limited, prioritizing equipment to determine how resources should be distributed is essential [5]-[6]. Criticality evaluation and equipment ranking help to focus on the most critical equipment and can support the 
scheduling of maintenance tasks on machines with high utilization rates in order to minimize their unavailability and improve performance. A wrong classification can lead to less critical equipment being prioritized over critical equipment, leading to failures with more negative impact on production [7]. Therefore, appropriate equipment criticality assessment should be developed, used correctly and updated regularly for good maintenance management [7]. This assessment can be made through the support of computerized maintenance management systems (CMMSs). According to Rastegari and Mobin [8], previous researches indicate that decision support capability is often lacking in existing computerized maintenance management systems (CMMSs) and data collected by the systems are not completely used.

In the literature, several methods for different types of industries were found for equipment prioritization or classification based on equipment criticality evaluation. Some methods have a broader purpose, i.e., they aim to define equipment that requires more attention by maintenance management, without specifying the actions to be prioritized. The prioritization methods proposed in the literature to support TBM tasks scheduling usually have also the function of evaluating the need to perform this type of preventive maintenance (PM) on equipment ([6],[9]-[10]), decision that are commonly taken by analyzing equipment individually, performing a technical analysis and taking into account recommendation of manufacturers. Once strategies have been defined for equipment of the plant, the next step is to define priorities for the different tasks assigned to the maintenance department since maintenance resources are usually limited.

A method to prioritize equipment for improvement was proposed by Azadeh et al. [11]. However, the method is focused mainly on equipment performance results and does not assess the resources used by the equipment to reach the current performance. The equipment can have a high performance at the expense of a high frequency of TBM.

The main goal of the research presented in this paper was to contribute to the improvement of the maintenance management performance of a multinational company operating in the automotive sector, by developing methods to assess equipment criticality to be used in a CMMS for maintenance management support. The methods aim to answer questions of interest to practitioners such as: Which corrective (or preventive) maintenance tasks should be performed first? Which machine should be improved?

This research was structured into the development of two different methods: the first method aims to support the daily management of equipment maintenance tasks prioritizing equipment considering the impact of the equipment failure on business. The second method aims to identify low-performance equipment to be targeted for improvement actions and, therefore, support management of medium and long-term maintenance actions.

This paper is structured into seven sections. The following section, section 2, explains the research methodology. Section 3 presents a literature review on criticality assessment and equipment performance rankings (or classifications) in the scope of maintenance management. In section 4, the method developed to define priorities for corrective and preventive tasks is presented. Section 5 deals with the method to create an equipment performance ranking and its application considering 842 machines from the automotive company. In section 6 , a discussion is made about the proposed methods. The last section, Section 7, presents the conclusions and future work.

\section{Research methodology}

The assessment criteria for each method were defined taking into account the literature review and the multinational company context.

The automotive company runs 24 hours a day and maintenance technicians work in 3 shifts to support production lines. The company adopts Total Productive Maintenance methodology and, therefore, all manufacturing equipment have a preventive maintenance plan defined taking into account the recommendation of manufacturers and adjusted based on experience. The high amount of equipment and therefore the high amount of requests for maintenance make necessary defining priorities concerning corrective and time-based maintenance tasks. Performing equipment improvement projects is a practice in the company and, therefore, criticality assessment in terms of performance allows highlighting equipment for which improvement is more required.

To achieve the intended objectives, a project team was formed involving three researchers, the authors of this paper, and three members of the automotive company. The company's members were two maintenance managers and a computer engineer responsible for the CMMS development. The researchers firstly surveyed the context of the organization and set criteria for each objective. These criteria were further analyzed and discussed with the team members belonging to the company at meetings, and finally approved by them for adoption by the company.

After the selection of the methods to obtain the final 
score or classification by the researchers for each one of the set purpose, the validation was then made by the project team. It involved practical applications using data and information from the automotive company.

\section{Literature review}

The literature on criticality assessment has been reviewed to first identify possible methods that meet the established objectives. Then, in each relevant paper that presents a method for criticality assessment, the criteria used were analyzed against the objectives proposed in the respective paper. Finally, in order to identify the best technique/method to obtain the final score or classification based on the chosen criteria, the advantages and disadvantages of each technique/ method used in the literature were also analyzed.
This section was organized in two topics: the purpose of criticality assessment and the method used to evaluate the criticality.

\subsection{Criticality assessment purpose}

Criticality is a relative measure of the importance of an object based on some factors considered in a particular context [12]. Equipment criticality evaluation is used to define the degree of importance of equipment for maintenance management [13]. Several methods based on multi-criteria decision-making techniques are presented in the literature to define equipment criticality (Table 1.). The proposed methods have different outputs: some methods result in an equipment classification with several categories and others result in a ranking for equipment prioritization.

Table 1. Literature survey of equipment criticality assessment

\begin{tabular}{|c|c|c|c|c|}
\hline Authors(year) & Criteria & Tool(s) used & Focused area & Objective \\
\hline $\begin{array}{l}\text { Bevilacqua and } \\
\text { Braglia (2000) [14] }\end{array}$ & $\begin{array}{l}\text { * Safety } \\
\text { * Machine importance for the process } \\
\text { * Maintenance costs } \\
\text { * Failure frequency } \\
\text { * Downtime length }\end{array}$ & $\begin{array}{l}\text { Additive weighting } \\
\text { method } \\
\text { AHP }\end{array}$ & $\begin{array}{l}\text { Oil refinery } \\
\text { assets }\end{array}$ & $\begin{array}{l}\text { Equipment classification } \\
\text { for maintenance strategy } \\
\text { selection }\end{array}$ \\
\hline $\begin{array}{l}\text { Fernandez et al. } \\
\text { (2003) [1] }\end{array}$ & $\begin{array}{l}\text { * Downtime } \\
\text { * Failure frequency }\end{array}$ & Decision making grid & $\begin{array}{l}\text { Manufactur- } \\
\text { ing systems }\end{array}$ & $\begin{array}{l}\text { Decision Making Grid for } \\
\text { maintenance strategy } \\
\text { selection implemented in a } \\
\text { CMMS }\end{array}$ \\
\hline Labib (2004) [15] & $\begin{array}{l}\text { * Downtime } \\
\text { * Failure frequency }\end{array}$ & Decision making grid & $\begin{array}{l}\text { Manufactur- } \\
\text { ing systems }\end{array}$ & $\begin{array}{l}\text { Identification of worst per- } \\
\text { forming machines and main- } \\
\text { tenance strategy selection }\end{array}$ \\
\hline $\begin{array}{l}\text { Shahin and } \\
\text { Attarpour (2011) [16] }\end{array}$ & $\begin{array}{l}\text { * OEE -Overall equipment effectiveness } \\
\text { indicator } \\
\text { * Downtime or frequency }\end{array}$ & Decision making grid & $\begin{array}{l}\text { Manufactur- } \\
\text { ing systems }\end{array}$ & $\begin{array}{l}\text { Identification of worst } \\
\text { performing machines and } \\
\text { Maintenance strategy } \\
\text { selection }\end{array}$ \\
\hline $\begin{array}{l}\text { Stadnicka et al. } \\
\text { (2014) [7] }\end{array}$ & $\begin{array}{l}\text { * Machine working time (\%) } \\
\text { * } N^{0} \text { of failures } \\
\text { * Breakdown time } \\
\text { * Machine changeability } \\
\text { * Stability of the machine } \\
\text { * Influence on safety and environment }\end{array}$ & Additive weighting method & $\begin{array}{l}\text { Manufactur- } \\
\text { ing systems }\end{array}$ & $\begin{array}{l}\text { Equipment classification for } \\
\text { maintenance strategy selec- } \\
\text { tion - considering the impact } \\
\text { on environment and safety }\end{array}$ \\
\hline $\begin{array}{l}\text { Guo and Dong } \\
\text { (1997) [9] }\end{array}$ & $\begin{array}{l}\text { * Operating Conditions } \\
\text { * Equipment Antecedents } \\
\text { * Operating Environments } \\
\text { * Effects of Equipment Accidents }\end{array}$ & AHP, fuzzy clustering & $\begin{array}{l}\text { Manufactur- } \\
\text { ing systems }\end{array}$ & $\begin{array}{l}\text { Equipment prioritization for } \\
\text { maintenance strategy selec- } \\
\text { tion - considering the impact } \\
\text { on environment and safety }\end{array}$ \\
\hline $\begin{array}{l}\text { Khanlari et al. } \\
\text { (2008) [6] }\end{array}$ & $\begin{array}{l}\text { * Sensitivity of operation } \\
\text { * MTBF } \\
\text { * MTTR } \\
\text { * Availability of required parts } \\
\text { * Availability of required personnel } \\
\text { * Work load }\end{array}$ & Fuzzy rules & $\begin{array}{l}\text { Manufactur- } \\
\text { ing systems }\end{array}$ & $\begin{array}{l}\text { Equipment prioritization for } \\
\text { PM scheduling - verbal ex- } \\
\text { pressions are quantified and } \\
\text { used in decision making }\end{array}$ \\
\hline Li and Ni (2009) [18] & * Bottleneck and impact on throughput & Bottleneck impact factor & $\begin{array}{l}\text { Manufactur- } \\
\text { ing systems }\end{array}$ & $\begin{array}{l}\text { Equipment prioritization for } \\
\text { PM scheduling - throughput } \\
\text { bottleneck detection and } \\
\text { maintenance opportunity } \\
\text { planning }\end{array}$ \\
\hline
\end{tabular}




\begin{tabular}{|c|c|c|c|c|}
\hline $\begin{array}{l}\text { Saleh et al. (2015) } \\
\text { [19] }\end{array}$ & $\begin{array}{l}\text { * Risk } \\
\text { * Performance assurance } \\
\text { * User competence } \\
\text { * Costs } \\
\text { * Standards }\end{array}$ & $\begin{array}{l}\text { Quality Function Deployment } \\
\text { (QFD) }\end{array}$ & $\begin{array}{l}\text { Medical } \\
\text { equipment }\end{array}$ & $\begin{array}{l}\text { Equipment prioritization for } \\
\text { PM scheduling - framework } \\
\text { based on QFD }\end{array}$ \\
\hline $\begin{array}{l}\text { Jaderi et al. (2012) } \\
\text { [10] }\end{array}$ & $\begin{array}{l}\text { * Failure frequency } \\
\text { * Failure detection } \\
\text { * Failure severity } \\
\text { * Failure costs }\end{array}$ & $\begin{array}{l}\text { AHP } \\
\text { Delphi }\end{array}$ & $\begin{array}{l}\text { Oil refinery } \\
\text { assets }\end{array}$ & $\begin{array}{l}\text { Prioritization of equipment } \\
\text { for PM scheduling and CM in } \\
\text { order to reduce environmen- } \\
\text { tal and safety costs and risks }\end{array}$ \\
\hline $\begin{array}{l}\text { Hijes and Cartagena } \\
(2006) \text { [5] }\end{array}$ & $\begin{array}{l}\text { * Effect of failure } \\
\text { * Where and when failure might be } \\
\text { detected } \\
\text { * State of depuration of the effluent } \\
\text { * Potential risk for plant operators } \\
\text { * Existence of alternative equipment } \\
\text { * Functional regime of the equipment } \\
\text { * Other elements on the plant that may } \\
\text { be affected } \\
\text { * Labor effects } \\
\text { * Time needed to restore service } \\
\text { * MTTR } \\
\text { * Cost of repair } \\
\text { * MTBF }\end{array}$ & Additive weighting method & $\begin{array}{l}\text { Manufactur- } \\
\text { ing systems; } \\
\text { waste treat- } \\
\text { ment plant }\end{array}$ & $\begin{array}{l}\text { Equipment prioritization } \\
\text { to identify equipment that } \\
\text { should receive greater atten- } \\
\text { tion by maintenance (level of } \\
\text { maintenance to be applied) }\end{array}$ \\
\hline $\begin{array}{l}\text { Singh and Kulkarni } \\
\text { (2013) [20] }\end{array}$ & $\begin{array}{l}\text { * Environmental impact } \\
\text { * Customer inconvenience } \\
\text { * Maintenance costs. }\end{array}$ & AHP & $\begin{array}{l}\text { Thermal } \\
\text { power plants } \\
\text { equipment }\end{array}$ & $\begin{array}{l}\text { Equipment prioritization } \\
\text { to identify equipment that } \\
\text { should receive greater atten- } \\
\text { tion by maintenance }\end{array}$ \\
\hline Qi et al. (2013) [21] & $\begin{array}{l}\text { * Effect on Environment } \\
\text { * Health and Safety } \\
\text { * Impact on business (shutdown duration) } \\
\text { * maintenance impact (costs) }\end{array}$ & $\begin{array}{l}\text { Additive weighted method } \\
\text { Fuzzy logic }\end{array}$ & $\begin{array}{l}\text { Chemical } \\
\text { plants equip- } \\
\text { ment }\end{array}$ & $\begin{array}{l}\text { Equipment prioritization } \\
\text { to identify equipment that } \\
\text { should receive greater atten- } \\
\text { tion by maintenance }\end{array}$ \\
\hline $\begin{array}{l}\text { Jagtap and Bewoor } \\
\text { (2017) [22] }\end{array}$ & $\begin{array}{l}\text { * Effect on power generation } \\
\text { * Environment and safety } \\
\text { * Frequency of failure } \\
\text { * Maintenance costs }\end{array}$ & AHP & $\begin{array}{l}\text { Thermal } \\
\text { power plants } \\
\text { equipment }\end{array}$ & $\begin{array}{l}\text { Equipment prioritization } \\
\text { to identify equipment that } \\
\text { should receive greater atten- } \\
\text { tion by maintenance }\end{array}$ \\
\hline $\begin{array}{l}\text { Márquez et al. } \\
\text { (2009) [23] }\end{array}$ & $\begin{array}{l}\text { * Environment } \\
\text { * Safety } \\
\text { * Quality } \\
\text { * Working Time } \\
\text { * Delivery } \\
\text { * Reliability } \\
\text { * Maintainability }\end{array}$ & Set of rules & - & $\begin{array}{l}\text { Define equipment categories } \\
\text { and respective mainte- } \\
\text { nance strategy (actions or } \\
\text { maintenance management } \\
\text { procedure) }\end{array}$ \\
\hline $\begin{array}{l}\text { Guo et al. (2009) } \\
\text { [24] }\end{array}$ & $\begin{array}{l}\text { * Production Loss } \\
\text { * Safety effect } \\
\text { * Environment effect } \\
\text { * Maintenance cost }\end{array}$ & Fuzzy and BP neural & $\begin{array}{l}\text { Petrochem- } \\
\text { ical equip- } \\
\text { ment }\end{array}$ & $\begin{array}{l}\text { Equipment prioritization to } \\
\text { be used in RCM and prevent } \\
\text { accidents. }\end{array}$ \\
\hline $\begin{array}{l}\text { Faisall and Sharawi } \\
\text { (2015) [25] }\end{array}$ & $\begin{array}{l}\text { * Support availability } \\
\text { * Performance } \\
\text { * Maintenance cost } \\
\text { * Age } \\
\text { * Function } \\
\text { * Operational impact } \\
\text { * Clinical acceptability }\end{array}$ & AHP & $\begin{array}{l}\text { Medical } \\
\text { equipment }\end{array}$ & $\begin{array}{l}\text { Prioritization of equipment } \\
\text { for replacement }\end{array}$ \\
\hline $\begin{array}{l}\text { Azadeh et al. (2007) } \\
\text { [11] }\end{array}$ & $\begin{array}{l}\text { * Availability } \\
\text { * Operating time to max time } \\
\text { * Available time to max time } \\
\text { * Inefficient time to available time } \\
\text { * Inefficient time to operation time } \\
\text { * Downtime to available time } \\
\text { * Downtime to operating time } \\
\text { * Downtime to inefficient time } \\
\text { * Value added to operating time } \\
\text { * Production value to operating time }\end{array}$ & $\begin{array}{l}\text { Principal Component Analysis } \\
\text { (PCA) } \\
\text { Data Envelopment Analysis } \\
\text { (DEA) }\end{array}$ & $\begin{array}{l}\text { Manufactur- } \\
\text { ing systems }\end{array}$ & $\begin{array}{l}\text { Prioritization based on per- } \\
\text { formance for improvement } \\
\text { of manufacturing systems }\end{array}$ \\
\hline $\begin{array}{l}\text { Taghipour et al. } \\
\text { (2010) [12] }\end{array}$ & $\begin{array}{l}\text { * Function } \\
\text { * Mission criticality } \\
\text { * Age } \\
\text { * Risk } \\
\text { * Recalls and hazard alerts } \\
\text { * Maintenance requirements }\end{array}$ & AHP & $\begin{array}{l}\text { Medical } \\
\text { equipment }\end{array}$ & $\begin{array}{l}\text { Prioritization of equip- } \\
\text { ment to be included in } \\
\text { maintenance management } \\
\text { programs to perform actions, } \\
\text { such as: user training; } \\
\text { preventive maintenance, } \\
\text { redesigning the device, etc. }\end{array}$ \\
\hline
\end{tabular}


In Table 1, the collected papers are grouped based on the classification or prioritization objective and sorted by the publication year.

Themorefrequentobjectivesassociated withequipment criticality assessment found in the literature are:

- Maintenance strategy selection;

- $\quad$ Preventive maintenance (PM) tasks scheduling;

- Identification of equipment that should receive greater attention by maintenance.

Methods based on equipment criticality for maintenance strategy selection were proposed by Bevilacqua and Braglia [14], Fernandez et al. [1], Labib [15], Shahin and Attarpour [16] and Stadnicka et al. [7]. Labib [15] proposed a model to be linked to a computerized maintenance management system to support decision making. The model is based on two criteria, i.e., downtime and failure frequency, that form a decision maturity grid (DMG). The DMG proposes different maintenance strategies for machines based on their states in the grid and allows identifying the worst performing machines for a certain period of time. The considered maintenance strategies are the following: run to failure; skill level upgrade; condition-based monitoring; design out maintenance; and time-based maintenance.

Shahin and Attarpour [16] modified the decision making grid presented by Labib [15] to include the Overall Equipment Effectiveness (OEE) indicator. The authors presented two solutions: a decision-making grid that considers the indicators Mean Time To Repair (MTTR) and Mean Time Between Failures (MTBF) and another decision making grid where MTBF was replaced by OEE. This method has the advantage of using well-known equipment performance indicators such as MTBF, MTTR and OEE. MTBF is determined calculating the average operating time between failures, MTTR is the average time to repair and OEE is obtained by the product of three factors (Availability, Performance and Quality). The disadvantage of these solutions is that they only consider two criteria at a time.

Bevilacqua and Braglia [14] defined a criticality index to classify equipment of an Italian oil refinery plant in three groups for assigning the best maintenance strategy to each group. In addition to failure frequency and downtime, the criticality index also considers the criteria: Safety, machine importance for the process and maintenance costs. Guo and Dong [9] and Stadnicka et al. [7] consider the impact of equipment failure on environment and safety.

The methods proposed by Khanlari et al. [6], Li and Ni [18] and Saleh et al. [19] aim at support PM scheduling. Khanlari et al. [6] as in [16] use MTBF and MTTR indicators to define criticality, as well as availability of resources to perform the preventive task, the work load and operation sensitivity. In short, the criteria considered in the criticality assessment method in addition to assess equipment performance and maintenance results through two indicators, also assess the possibility of carrying out the task at the considered time and the impact of a possible equipment failure. $\mathrm{Li}$ and $\mathrm{Ni}$ [18] defined criticality based on the impact of the equipment failure have on throughput. Therefore, their method is focused on the bottleneck station, considering that high priority must be given to maintain the bottleneck station in good operating state to improve system performance. Equipment prioritization is defined in [10] for both PM and corrective maintenance (CM). Like in the previous cited works, the prioritization of tasks is set by the priority assigned to the equipment as a whole. However, some preventive tasks regarding critical equipment are not necessarily critical since the failures they intend to avoid may not have a significant impact on equipment performance.

In general, except for $\mathrm{Li}$ and $\mathrm{Ni}$ [18], the proposed methods for PM seem to be defined to answer two different questions at the same time: it is worth doing PM on the equipment (PM strategy selection)? In what order should it be scheduled, considering limited resources? One of the two objectives set in this paper is prioritizing PM tasks, but it is considered that these tasks have already been defined for the equipment.

Singh and Kulkarni [20], Qi et al. [21] and Jagtap and Bewoor [22] prioritize equipment based on criticality for thermal and chemical equipment with a more comprehensive purpose: identification of equipment that should receive greater attention by maintenance. Hijes and Cartagena [5] also proposed a method with the same purpose for manufacturing systems with an extensive number of criteria.

In some other works, the proposed equipment criticality assessment methods have some other goals, such as: Define maintenance management procedures for equipment [23]; Define maintenance plans to prevent accidents through the use of Reliability Centered Maintenance (RCM) methodology [24]; Decision making about replacement [25]; Select the more critical medical devices to be included in the equipment management program of a hospital [12].

Azadeh et al. [11] was the only work found with the explicit aim of improving manufacturing equipment performance. The proposed method uses equipment performance indicators related to machine productivity. However, the equipment ranking does not 
highlight the effort to be made to obtain a high performance, such as time spent on preventive maintenance and spare parts costs and, in addition, the impact on product quality is also not considered explicitly. The indicators on which the method is based are not commonly monitored in the maintenance area, which may make the method more difficult to implement.

Table 1 allows highlighting that there is no pattern in the type of criteria used in relation to the objective established for the criticality assessment. For instance, "failure frequency", is used in [15] for prioritizing equipment to select maintenance strategies, in [10] to prioritize PM and CM and in [22] to identify equipment to be subject to more attention by maintenance.

\subsection{Methods used for criticality assessment}

Based on the selected criteria, different methods are used to define equipment categories or groups or to define a ranking, such as: rules ([15],[6]), fuzzy clustering, additive weighting method ([5], [7]) and Analytical Hierarchy Process ([14], [20], [12], [22]). See third column in Table 1.

Rules are used with the purpose of obtaining different equipment groups or categories. This is an adequate method to manage a great amount of equipment taking into account its similarities, defining common strategies and procedures such as in [23], [15]. Khanlari et al. [6] combined rules with fuzzy logic.

The fuzzy clustering is also presented in the literature as a possible method to assess equipment importance or criticality. Guo and Dong [9] presented a fuzzy clustering analysis framework divided in four sub-hierarchy models. Guo et al. [24] stated that fuzzy evaluation can better deal with imprecise information and this could be beneficial to the companies. However, its successful application depends on membership function and a set of weight factors. The fuzzy evaluation application has several advantages, however, this is a complex methodology and it is difficult to develop because it requires several simulations before use [17].

The Analytic Hierarchy Process (AHP) is one of the most popular multi-criteria decision-making techniques and is a flexible tool that enables to integrate qualitative aspects together with quantitative ones [27]. AHP is usually used when the purpose is to determine the best alternative but it can also be used when it is expected to determine the relative importance of all contemplated alternatives [28]. When AHP is used to create a ranking, the alternatives are evaluated by selecting the appropriate range on each criterion [29]. This methodology is used in a wide range of fields, especially in operations management, to solve complex decision problems by the prioritization of alternatives [30]-[31]. AHP is able to manage a large number of alternatives efficiently so it can be used to rank a large amount of machines [14].

Subramanian and Ramanathan [31] stated that almost more than 50\% of AHP applications are integrated with other methodologies and one of these methodologies is the Delphi method. The Delphi method is a structured communication technique which relies on a panel of experts. Jaderi et al. [10] conducted a case study in an oil refinery and applied AHP and Delphi techniques to define equipment priority. The Delphi group created by Jaderi et al. [10] counted with nine participants: five experts and four scholars. In their case study, the Delphi technique was applied to define the scales and classifications for each criterion and to identify the relative importance between criteria. However, the use of Delphi method is not always possible because it is difficult to have people available in companies to participate in the Delphi group.

Singh and Kulkarni [20] and Jagtap and Bewoor [22] rank thermal power plant equipment using AHP. The framework for medical devices prioritization proposed by Taghipour et al. [12] also uses AHP.

AHP makes possible to measure the consistency of the decision maker [14]. The calculation of consistency ratios makes the method more reliable when compared to the additive weighting method where the criteria weights are directly assigned. With simple additive method the revealed estimates do not always reflect the real situation and the results obtained may not be logical [17].

\section{Maintenance tasks prioritization to daily equipment maintenance management}

The development of the method to prioritize corrective and preventive maintenance tasks started with the definition of some requirements by the project team, as follows:

- $\quad$ The method should not be time consuming so that the prioritization process is cost-effective.

- Contrary to what is presented in the literature, the criticality assessment should be done at the task level, not at the equipment level, since a failure mode of critical equipment may not be critical.

- Concerning corrective maintenance tasks, 
the machines with higher utilization and the repairs that have more impact in production have to be prioritized over the others since, in these cases, the production process has less capacity to recover and meet deadlines.

- $\quad$ For the same reason of the previous requirements, preventive maintenance tasks should also be performed first on machines whose potential failures have the greatest impact on productivity.

Taking into account the requirements, it was defined that the proposed method should use a set of criteria to first assign a criticality to the machine, considering the combination of values taken in each criterion (Figure 1). Then, for each type of maintenance tasks, corrective or time-based, other criteria should be subsequently added, to define its criticality.

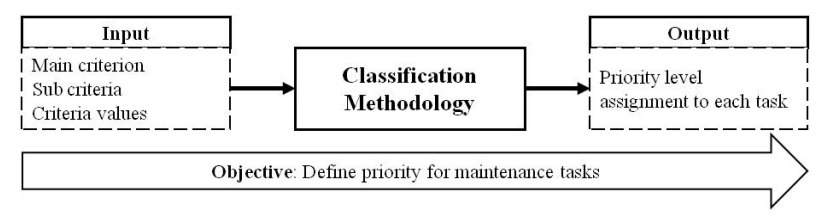

Figure 1. Tasks prioritization process

The definition of criteria for equipment criticality determination was made taking into account the impact in productivity of equipment stoppage, since the aim is to define priorities to allow the fulfillment of the current production requests. The assignment of a low priority means that the maintenance task will wait longer to be performed.

Therefore, the criterion designated by Business Impact Rating (BIR), which assesses the impact of downtime on productivity, was defined. This approach is similar to that proposed by $\mathrm{Li}$ and $\mathrm{Ni}[18]$ that assigns a high priority to PM tasks of bottleneck station. Taghipour et al. [12] use a similar factor called "Mission criticality" as part of their method for medical device selection to be included in the maintenance program of a hospital.

The BIR criterion is composed by two sub-criteria, equipment utilization (CA) and availability of alternative machines (CB), as presented in Figure 2, and its value is set by the use of rules.

The "equipment utilization" sub-criterion (CA) expresses the criticality or importance of the production line where the equipment operates. A line that is being used more than other lines is more critical since it has less time available for maintenance tasks and has less capacity slack to be able to recover from downtimes and meet deadlines, when delays occur. This sub-criterion quantifies the utilization time of the equipment per week. The sub-criterion "availability of alternative machines" (CB) intends to indicate if there are machines in the production line that can do the same operations as the machine that is being assessed. The existence of alternative machines can decrease the impact of a breakdown since production can continue, using or increasing productivity of the other machines.

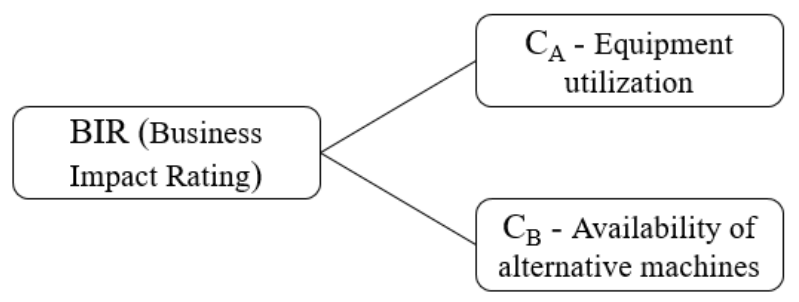

Figure 2. Selected criteria for equipment classification

The ranges for each sub-criterion and the corresponding levels for the case study company, defined with its support, are presented in Figure 3.

\begin{tabular}{|c|c|c|c|c|}
\cline { 3 - 4 } \multicolumn{2}{c|}{} & \multicolumn{2}{c|}{$\mathbf{C}_{B}$} \\
\cline { 4 - 5 } \multicolumn{2}{c|}{} & Has at least an alternative machine & Single machine \\
\hline \multirow{3}{*}{$C_{A}$} & 1 & $\leq 84 \mathrm{~h}$ per week & 1 & 2 \\
\cline { 2 - 5 } & 2 & $>84$ h and $\leq 126 \mathrm{~h}$ per week & 2 & 3 \\
\cline { 2 - 5 } & 3 & $>126 \mathrm{~h}$ per week & 3 & 4 \\
\hline
\end{tabular}

Figure 3. Business Impact Rating value and criteria ranges

During the development of the method, each combination of levels of the two criteria was analyzed in order to define rules that would allow assigning a classification to each machine. After the analysis of the criteria combinations, a classification with four levels was assigned, obtaining the values for the BIR criterion, as presented in Figure 3. For some combinations, the same BIR value has been associated since it was considered that it represents situations with similar impact on productivity.

For corrective maintenance tasks prioritization, the BIR value of the equipment is considered together with a criterion related to failure impact on production, as shown in Figure 4. 


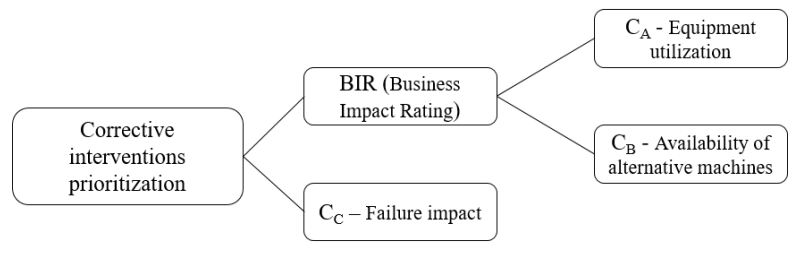

Figure 4. Criteria for corrective tasks prioritization

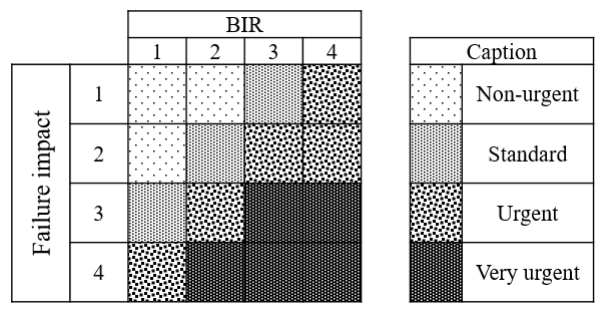

Figure 5. Classification grid for corrective actions
Since the main objective of the classification is to prioritize corrective tasks, the impact that the failure has in the production line has to be considered. The failure impact is assessed by the criterion CC "machine status after failure" that intends to transmit the effect that each failure has in production. The indication of the impact of failures on production will be informed by the operator or by the line head at the same time they communicate the failure to maintenance department and register its occurrence in the CMMS. The criterion CC is composed by four levels, as presented in Table 2, which represent the different possible consequences of a failure. Level 1 and level 4 represent respectively the smallest and greatest impact in terms of productivity. The intermediate levels represent two different failure consequences when equipment is still working. For level 2, the impact is verified by a reduction in machine speed or by small downtimes and for level 3 , the production of nonconforming products reduces the machine yield. In situations where both impacts are verified, level 3 should be selected since it implies additional costs associated with rework or scrap of nonconforming products.

Table 2. Ranges and corresponding levels of Cc criterion

\begin{tabular}{cc}
\hline Level & Cc - Machine status after failure \\
\hline 1 & Working (100\%) \\
2 & Performance loss \\
3 & Working with high probability of quality problems \\
4 & Stopped \\
\hline
\end{tabular}

The combination of BIR value and $\mathrm{Cc}$ criterion was analyzed by the project team and the prioritization for corrective maintenance was defined as shown in Figure 5. Hence, taking into account this classification grid for corrective actions, if several machines need a corrective maintenance task at the same time, the machines with higher classification will be repaired first. Four levels of priority have been defined by the combination of the criteria: "very urgent", "urgent", "standard" and "Non-urgent". The defined classification allows the reduction of the impact of unscheduled maintenance on productivity since machines most requested or occupied have priority in performing repairs and this priority is higher depending on the impact of failure on production. As indicated by figure 5, failures with a higher impact (Cc level) or machines with higher BIR value have a higher priority. Failures that do not originate a production stoppage have the lowest priority when verified in machines with a BIR value of 1 or 2 , since it will not compromise the achievement of production objectives.

This classification for repair requests is useful to establish priorities automatically and in real time.

The defined classification allows the reduction of the impact of unscheduled maintenance on productivity since machines most requested or occupied have priority in performing repairs and this priority is higher depending on the impact of failure on production. As indicated by figure 5, failures with a higher impact (Cc level) or machines with higher BIR value have a higher priority. Failures that do not originate a production stoppage have the lowest priority when verified in machines with a BIR value of 1 or 2 , since it will not compromise the achievement of production objectives.

This classification for repair requests is useful to establish priorities automatically and in real time. Based on the record made by the operator requiring a maintenance task, the CMMS will inform technicians about the machines that have to be repaired first and the technicians' coordinator does not have to do this prioritization as he did in the case study company. This information can be highlighted in different colors in CMMS to an easy identification of priorities.

The classification grid for corrective actions was tested using data concerning corrective actions from the automotive company. For the application case, a set of 9 maintenance tasks associated to different machines and production lines was considered and is presented in Table 3. For each maintenance task the BIR (Business Impact Rating) and a Cc (Failure Impact) criteria are registered in the table. The table includes the designation of the corrective maintenance tasks as recorded by the maintenance technicians in the CMMS and represents the performed actions to solve the reported failure.

The combination of the BIR value and $\mathrm{Cc}$ criteria was analyzed taking into account the classi- 
fication grid for corrective tasks presented in Figure 5. The final priority classification for each corrective maintenance task is presented in Table 3.

The corrective tasks considered in the application case represent different possible combinations of the criteria. From Table 3, the classification identified that tasks associated to the GP01, GP02 and ASY10_0010 machines have priority over the remaining maintenance tasks. However, the method does not differentiate between the "very urgent" tasks when this priority level is assigned to more than one task. In this case, the choice may be taken based on the task that is expected to have a shorter duration or on other information about the line or production order, such as the delivery time or the estimated production loss per unit of time.

The three members of the automotive company belonging to the project team approved this method recognizing that the priorities as assigned, enable the fulfillment of their goals.

Concerning preventive (or time-based) maintenance tasks, a similar classification process was done to support maintenance scheduling. In the case study company, as in many other companies [32], the frequency of preventive maintenance is defined based on manufacturer recommendations and adjusted based on technicians' experience. Therefore, the objective of preventive tasks scheduling is to avoid delays compared to the predefined dates. The ordering of preventive tasks is the first step in the maintenance scheduling activity. After, for the scheduling period, the priority tasks should be scheduled first in the machines downtime intervals. The BIR indicator will be used for the ordering of tasks. A machine with a high BIR value means that this machine has less opportunity to stop and has short stoppages. Therefore, associated critical preventive maintenance tasks should be performed as needed and as soon as possible in the machine planned downtime. As presented in Figure 6 , the BIR will be used together with two other criteria: due date and task criticality. Task criticality indicates the state of the machine if the failure is not avoided. The task criticality will have the same levels as the factor Cc. However, the task criticality is not indicated by the operators when the failure occurs as for $\mathrm{Cc}$, it is an information that should be recorded associated to each failure mode. In companies that adopt the FMEA tool for reliability analysis, the impact of each failure mode is recorded to define the value of the severity factor of the RPN indicator. Therefore, the task criticality can be obtained from this tool.

For preventive maintenance tasks prioritization, a decision tree will be used considering the three factors (BIR; due date and tasks criticality). Concerning the due date factor, the ranges should consider the time interval between preventive tasks since the impact of delays is dependent of this period. Therefore, the delay factor can be defined as a percentage of the interval between preventive tasks. Each company should define its suitable ranges and corresponding decision tree.

This prioritization of PM tasks is not yet implemented in the company, since tasks criticality should be recorded, integrated in the FMEA tool, and this record will be made progressively since a great amount of equipment and therefore a great amount of tasks is involved.

To start using the BIR indicator for maintenance tasks prioritization, information about the machine and the line where it is integrated should be recorded and available in the CMMS. Whenever a new production line is deployed or whenever changes are made in a current line in terms of machines that integrate it, the information must be recorded or changed, i.e., the machines should be associated with the respective production line and machines with the same func-

Table 3. Application of the classification grid for corrective actions

\begin{tabular}{|c|c|c|c|c|c|}
\hline Equipment & & & Maintenance Tasks & & \\
\hline Line & Designation & $\mathrm{BIR}$ & Designation & $\mathrm{Cc}$ & Priority \\
\hline 2N16 & GP01 & 4 & $\begin{array}{l}\text { Replacing the stator and rotor of } \\
\text { the dispensing Pump }\end{array}$ & 3 & Very Urgent \\
\hline $2 \mathrm{M} 05$ & VT17 & 4 & Cleaning the flow tank & 1 & Non Urgent \\
\hline 2N16 & GP02 & 4 & Curtains replacement in EPM's & 4 & Very Urgent \\
\hline $2 \mathrm{~N} 05$ & ASY10_0010 & 3 & $\begin{array}{l}\text { Replacing Vacuum Pumps (suc- } \\
\text { tion cups) }\end{array}$ & 3 & Very Urgent \\
\hline $2 \mathrm{~N} 05$ & FCT50_0010 & 2 & Replace interface needles & 3 & Urgent \\
\hline $2 \mathrm{~N} 05$ & FCT50_0015 & 2 & Internal cleanliness & 2 & Standard \\
\hline 2105 & BUR50_0301 & 1 & $\begin{array}{l}\text { Bolting of guides and suction } \\
\text { cups }\end{array}$ & 1 & Non Urgent \\
\hline 2105 & BUR50_0310 & 1 & O-ring replacement & 3 & Standard \\
\hline 2105 & BUR50_0301 & 1 & Cleaning the oven glasses & 1 & Non Urgent \\
\hline
\end{tabular}




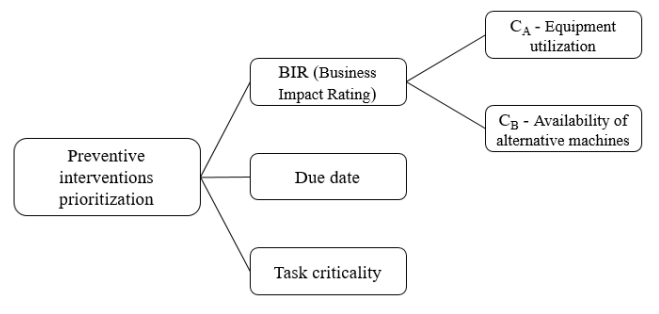

Figure 6. Factors for preventive tasks prioritization

tion should be identified. In addition, concerning the $\mathrm{CA}$ factor, the operating time per week must be recorded and updated whenever this operating time changes. Regarding the failure impact, the information required to implement the presented method is introduced by the production line leader and has to be accurate because it has a great impact on the method results. The options about production line status that are presented to line leader may be suggested by the system depending on the type of failure reported.

\section{Equipment ranking based on performance for improvement actions prioritization}

The equipment performance ranking proposed in this paper consists of a general evaluation of equipment performance that is able to identify the worst-performing equipment. This ranking aims to prioritize improvement actions on equipment considering its current performance. In this section, the assessment methodology is first explained and then applied to a set of machines of the automotive company.

\subsection{The assessment method}

The technique chosen to define the performance ranking was AHP since, based on the literature review, the researchers considered that it is the most appropriate method to make a general evaluation of the equipment performance considering the effort made to reduce failures. The expected inputs and outputs are presented in Figure 7.

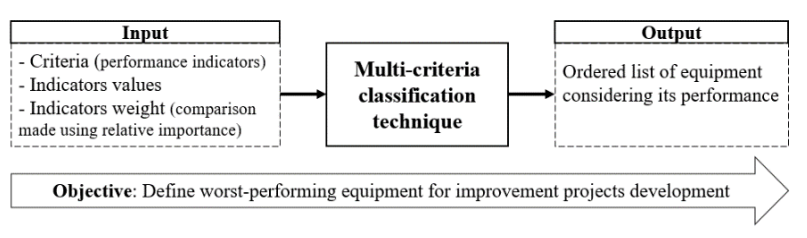

Figure 7. Equipment performance ranking process
The proposed method considers both relative and absolute measurement in the AHP application. The large number of machines (alternatives) makes it impossible to perform comparisons between machines for each criterion. Considering this, each machine is assessed with respect to each criterion, to which a weight is assigned, without comparing it with other machines. The following steps have been considered for the method development and implementation:

1. Identify and select the criteria to evaluate equipment performance;

2. Define a weight (wi) for each criterion using the relative measurement method;

3. Verify the weights consistency;

4. Define ranges for each criterion and determine the idealized priority for each range;

5. Calculate the ranking score for each machine;

6. Sort the machines according to the scores.

The criteria chosen to develop this ranking are presented in Table 4. The indicators Mean Time Between Failures (MTBF) and Mean Time To Repair (MTTR) have been selected as assessment criteria, such as proposed by Labib (2004).

Table 4. Performance criteria

\begin{tabular}{|c|c|c|c|}
\hline & Name & Expression & Measure unit \\
\hline $\mathrm{C}_{1}$ & $\begin{array}{c}\text { Mean Time } \\
\text { Between Failures } \\
\text { (MTBF) }\end{array}$ & $\begin{array}{l}\text { Total operating } \\
\text { time/Total } n^{\circ} \text { of } \\
\text { failures }\end{array}$ & Minutes \\
\hline $\mathrm{C}_{2}$ & $\begin{array}{l}\text { Mean Time To } \\
\text { Repair (MTTR) }\end{array}$ & $\begin{array}{l}\text { Total repair time/ } \\
\text { Total nº of failures }\end{array}$ & Minutes \\
\hline $\mathrm{C} 3$ & $\begin{array}{l}\text { Total time used } \\
\text { in preventive } \\
\text { maintenance }\end{array}$ & $\begin{array}{c}\text { Sum of time used } \\
\text { in preventive } \\
\text { actions }\end{array}$ & Hours \\
\hline $\mathrm{C}_{4}$ & Quality rate & $\begin{array}{l}\text { (Total } n^{\circ} \text { produced } \\
-\mathrm{n}^{\circ} \text { scrapped)/To- } \\
\text { tal } n^{\circ} \text { produced }\end{array}$ & $\%$ \\
\hline $\mathrm{C}_{5}$ & Spare parts costs & $\begin{array}{l}\text { Sum of costs of } \\
\text { spare parts used }\end{array}$ & Euros \\
\hline
\end{tabular}

Since high availability of manufacturing machines is required, time between failures should be high and time to repair should be low. The performance of equipment is also measured by its quality rate as considered by the OEE indicator. A failure mode may not lead to a breakdown, but may originate non-conforming products. Thus, Quality rate was considered as a criterion. Besides, equipment may be subject to preventive maintenance, having an impact on costs. A machine may have a high time between failures due to a high cost spent on preventive maintenance. Therefore, the total time used in preventive maintenance and spare parts costs are also considered as criteria. 
Such as in [12], the definition of criteria weights is made through comparisons between criteria considering the scale of relative importance proposed by Saaty [33] presented in Table 5.

In this case, the "activities" are the criteria and the scale is used to compare the importance of each criterion against the ranking objective.

A matrix, designated by judgment matrix, is built with the relative importance values. The weight of each criterion is calculated using equation (1).

$$
w_{i}=\frac{\sqrt[n]{\prod_{j=1}^{n} a_{i j}}}{\sum_{i=1}^{n} \sqrt[n]{\prod_{j=1}^{n} a_{i j}}}
$$

The vector composed by the weight of each criterion is called the priority vector. In (1), aij is the value of the relative importance between criterion $\mathrm{i}$ and criterion $\mathrm{j}$, element of the judgment matrix, and $\mathrm{n}$ is the number of criteria or the matrix size.

To verify the consistency of the pairwise comparisons, the Consistency Ratio (CR) is determined and it has to be less than $10 \%$. The CR is obtained by dividing the Consistency Index (CI) value by the Random Consistency Index (RCI). The CI is calculated using equation (2).

$$
C I=\frac{\lambda_{\max }-n}{n-1}
$$

The value of $\lambda \max$ is obtained by adding the columns elements in the judgment matrix and multiplying the resulting vector by the priority vector. The RCI is given in Table 6 as a function of $n$.

After defining weights and verifying consistency, the ranges inside each criterion are defined. The relative measurement method adopted by [12] is used to determine the idealized priority of each range inside the scale used for each criterion.

The idealized priority of each range in the scale can be obtained by dividing each range's weight by the maximum weight. Consequently, if a machine is included in the range with highest idealized priority with respect to a criterion, the criterion contributes with its full capacity to the ranking score. After defining criteria, weights, ranges and corresponding idealized priorities, scores are calculated for each equipment and, based on these scores, equipment are sorted in descending order.
Table 5. Scale of relative importance (according to Saaty [33])

\begin{tabular}{lll}
\hline $\begin{array}{l}\text { Intensity of } \\
\text { importance }\end{array}$ & Definition & Explanation
\end{tabular}

1

1

Equal importance

Two activities contribute equally to the objective

$3 \quad$ Weak importance of one over another

5 Essential or strong
importance

Experience and judgment strongly favor one activity over another

An activity is strongly favored and its dominance demonstrated in practice

The evidence favoring one activity over another is of the highest possible order of affirmation

Intermediate values
between the two adja-
cent judgments

When compromise is needed
Table 6. $\mathrm{RCl}$ values for different values of $\mathrm{n}$ (according to Saaty [33])

\begin{tabular}{llllllllll}
\hline $\mathrm{N}$ & 1 & 2 & 3 & 4 & 5 & 6 & 7 & 8 & 9 \\
\hline $\mathrm{NRC}$ & 0 & 0 & 0.58 & 0.9 & 1.12 & 1.24 & 1.32 & 1.41 & 1.45 \\
\hline
\end{tabular}




\subsection{Practical application}

The method and respective defined criteria were tested using data collected in a group of machines from the automotive company. The application example was carried out for 842 machines. The data needed to carry out the ranking, although dispersed in different information systems, was available. Data about Quality rate and spare parts costs was not available in the CMMS. This data was available in the ERP system. In the future, in order to automate the gathering of information, the software application to define priorities would be integrated with the ERP system and CMMS of the company.

For each criterion a weight was defined through pairwise comparisons using the scale of relative importance proposed by Saaty [33]. The pairwise comparisons were defined at a meeting including the maintenance managers and other members of the maintenance department as well as the researchers. The obtained values are presented in Table 7 .

Taking into account these pairwise comparisons, the obtained priority vector was $(0.398$; $0.111 ; 0.055 ; 0.398 ; 0.037)$ as indicated in Table 7.

The consistency of these pairwise comparisons was analysed and the following values were obtained: $\square \max =5.12, \mathrm{CI}=0.03$ and $\mathrm{CR}=0.027$ (2.7\%). As the $\mathrm{CR}$ is less than $10 \%$, the pairwise comparisons were considered consistent. Table 7 shows that the biggest weights were assigned to the indicator Mean Time Between Failure (MTBF) and to Quality rate with a value of 0.398. Costs of spare parts and time spent on preventive maintenance have lower associated weights.

This situation can be explained by the fact that generally the cost of production loss far exceeds the cost associated with spare parts and that preventive maintenance can be performed during equipment downtime.

Each criterion was divided into a scale with five ranges, as presented in Table 8 . The ranges were defined in collaboration with the maintenance managers, analyzing the records about each criterion. The definition of the lower limit for the worst range is especially important for the classification. Too many equipment in the last range of each criterion may lead to equipment with the same final rating. Considering the defined ranges, the following numbers of machines were verified in the last range of each criterion:

- MTBF- 245machines

- MTTR-42machines;

- Total time used in preventive maintenance - 43 machines;

- Quality rate - 109 machines;

- $\quad$ Spare parts costs - 41 machines.
The measure unit used was "minute" for MTBF and MTTR since the information was provided in this unit and, for the total time of preventive maintenance, the unit is "hour" since it was not possible to obtain data with more precision. This criterion or indicator was not used by the company as well as the cost of spare parts, despite being available, and therefore their gathering was more complex. However, the lack of precision in this criterion did not affect the results.

To compute data and obtain a final rating based on the levels or ranges, a priority or weight was assigned to each range of the criterion designated by idealized priority. To determine the idealized priority of each range, it was assumed that the pairwise comparisons of the ranges inside each criterion are equal for every criterion. Each range was compared to other ranges through pairwise comparisons as presented in Table 9. After calculating the weights, each weight was divided by the maximum weight (in this case 0.510 ) to obtain the idealized priorities. Therefore, the value 1 will be assigned whenever the criterion value is contained in the worst level interval and the value 0,065, whenever the criterion value is contained in the best level.

The method was used to rank the 842 machines considered in this example. The five worst-performing machines are presented in Table 10. Taking into account the results shown in Table 10, the worst score obtained in this application was 0.916. The best score that can be achieved is 0.065 and this occurs if the machine is included in the lowest range for all criteria (idealized priority of lowest range is 0.065 for all criteria). This lowest score was achieved for 74 of the 842 machines that were analyzed.

The machines presented in Table 10 are all inspection equipment to test the manufactured product. FCT30_0272, FCT60_0402, FCT30_0270, and FCT50_0270 are inspection stations that test the functional characteristics, mainly electrical. The VTT50 machine tests the operation of the produced device at different temperatures. The first machine of the list and hence the machine with the worst performance was classified in the last range for all criteria except for the C3 criterion for which it was classified in the first range.

In this case, it can be checked if an increase in preventive maintenance frequency may reduce failures and then improve the performance. The same situation is verified for the second machine. The third machine was classified in the last ranges for $\mathrm{C} 1, \mathrm{C} 2$ and $\mathrm{C} 4$, in the second range for $\mathrm{C} 3$ and in the first range for $\mathrm{C} 5$. For this machine no spare parts were used in the analyzed period.

The same analysis performed in the following month also placed FCT30-0272 and FCT30-0270 in the list of the five worst machines. The data used in the application example correspond to one month of 
production. One month was considered in general adequate in this company due to the high production rate. However, for certain machines in order to obtain a better estimate of the indicators, the possibility of considering a longer time interval should be analyzed.

The recording of spare parts used in the maintenance tasks associated with the respective machines is mandatory in order to have the record of all parts used in each machine. The average unit cost of each spare part should also be available to calculate the total cost. This implies in the case study company a connection between the ERP system and the CMMS.
Concerning the criteria "total time spent on preventive maintenance", the time spent on each preventive task is available in the case study company and is also generally available in companies, recorded associated with the equipment or accessible in the activity records of maintenance technicians. Every month the values of the criteria are updated, which does not imply an additional task in the case study company concerning the MTBF, MTTR and Quality rate since these indicators are already used for maintenance and quality management.

Table 7. Pairwise comparison matrix and determination of priority vector

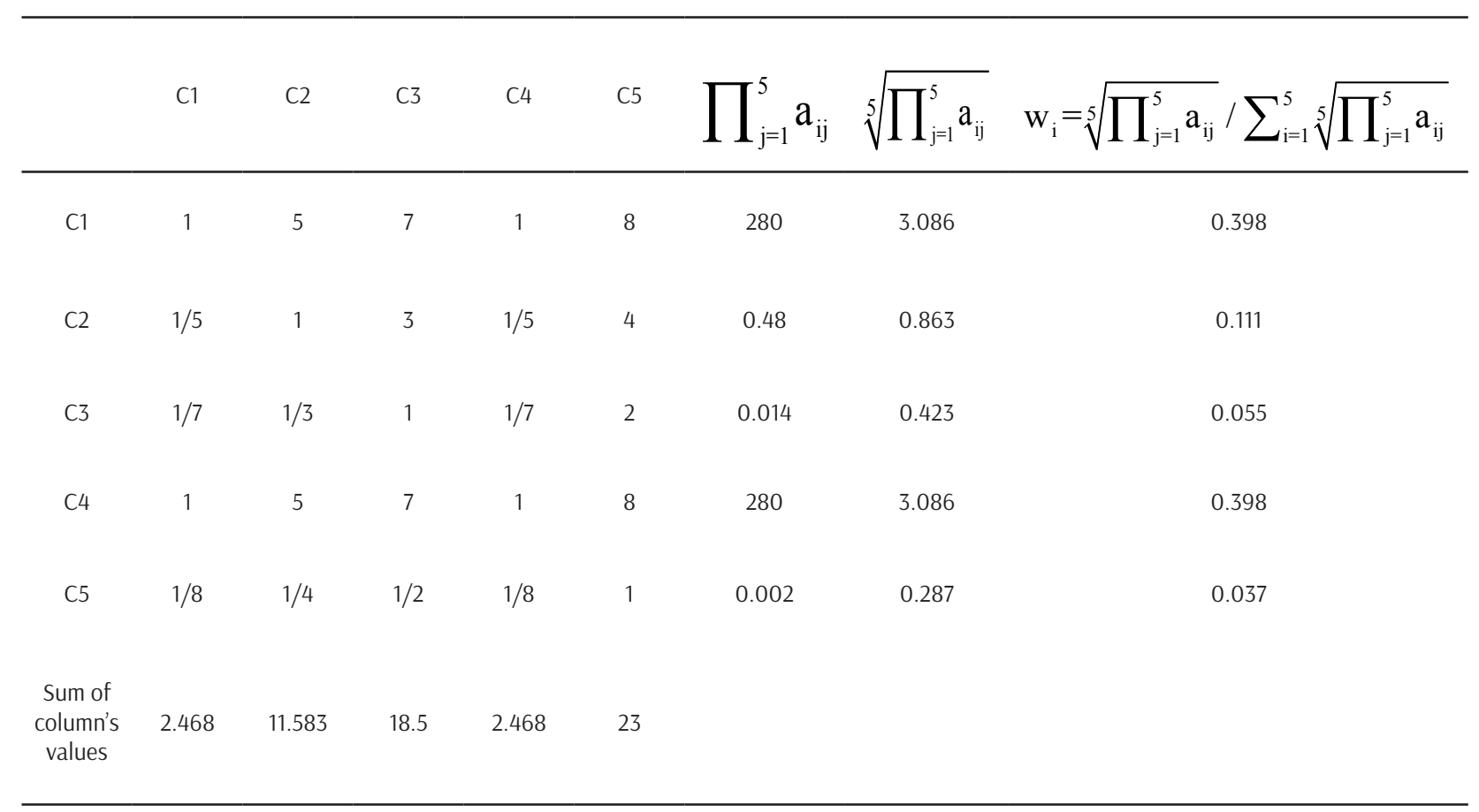

Table 8. Criteria ranges

\begin{tabular}{|c|c|c|c|c|c|}
\hline Range & $\mathrm{C}_{1}(\mathrm{~min})$ & $\mathrm{C}_{2}(\mathrm{~min})$ & $\mathrm{C}_{3}(\mathrm{~h})$ & $\mathrm{C}_{4}(\%)$ & $\mathrm{C}_{5}$ (EUR) \\
\hline 1 & $>8000$ & $\leq 15$ & $\leq 1$ & $>95$ & $\leq 50$ \\
\hline 2 & $6001-8000$ & $16-30$ & $1.1-4$ & $91-95$ & $50.01-200$ \\
\hline 3 & $4001-6000$ & $31-45$ & $4.1-7$ & $86-90$ & $200.01-350$ \\
\hline 4 & $2001-4000$ & $46-60$ & $7.1-10$ & $81-85$ & $350.01-500$ \\
\hline 5 & $\leq 2000$ & $>60$ & $>10$ & $\leq 80$ & $>500$ \\
\hline
\end{tabular}


Table 9. Comparisons between ranges and idealized priorities

\begin{tabular}{|c|c|c|c|c|c|c|c|}
\hline & 5 & 4 & 3 & 2 & 1 & Weight & Idealized priority \\
\hline 5 & 1 & 3 & 5 & 7 & 9 & 0.510 & 1 \\
\hline 4 & $1 / 3$ & 1 & 3 & 5 & 7 & 0.264 & 0.517 \\
\hline 3 & $1 / 5$ & $1 / 3$ & 1 & 3 & 5 & 0.130 & 0.254 \\
\hline 2 & $1 / 7$ & $1 / 5$ & $1 / 3$ & 1 & 3 & 0.064 & 0.125 \\
\hline 1 & $1 / 9$ & $1 / 7$ & $1 / 5$ & $1 / 3$ & 1 & 0.033 & 0.065 \\
\hline
\end{tabular}

Table 10. Performance ranking - five worst-performing machines

\begin{tabular}{ccc}
\hline Ranking & Machine & Score \\
\hline 1 & FCT30_0272 & 0,916 \\
2 & FCT60_0402 & 0,913 \\
3 & VTT50_0402 & 0,913 \\
4 & FCT30_0270 & 0,894 \\
5 & FCT50_0270 & 0,876 \\
\hline
\end{tabular}

\section{Discussion}

For manufacturing systems involved in production lines, preventive maintenance tasks are settled down to reduce equipment stoppage. The adoption of timebased maintenance for manufacturing equipment is a practice associated with the Total Productive Maintenance methodology. Cleaning the dust generated in the production process, lubrication and preventive replacement of mechanical parts are performed periodically since these tasks are usually effective in reducing the probability of failure, avoiding production losses originated associated with breakdowns.

Considering all the equipment in a manufacturing plant and the periodicity of each preventive maintenance task, when resources are limited, they have to be distributed and assigned to the requested tasks. This is a decision that must be taken in the short term. In the medium and long term, improvements of equipment performance could be made, beginning with the more critical ones.

In the literature, the same criteria are used in different methods of criticality assessment, although the objectives stated are different. In this paper, two distinct objectives for criticality assessment were defined and the criteria were aligned with the purpose of the classification or ranking. Therefore, the methods use different criteria and also different prioritizing methods.

The first objective, which is sequencing or prioritization of tasks in the plant when resources are limited, led to the development of a method for supporting daily maintenance management.

The second objective is the identification of worst-performing equipment for defining medium and long term actions for equipment improvement. Improvement may involve maintenance strategies changes, design and spare parts specification changes, or training, in order to improve reliability, maintainability and/or reduce costs. In the context of industry 4.0, it may consist of identifying in which equipment new and advanced technologies would be applied.

For the first method, the criticality assessment focuses on both equipment and task criticality since not all tasks of critical equipment are themselves critical, unlike the methods proposed in the literature that prioritize tasks based on equipment criticality.

The second method, that aims to identify worst-performing equipment, includes the assessment of the performance of the equipment, through the criteria or indicators "MTBF", "MTTR" and "quality rate", and the assessment of the effort made (or direct costs incurred) to obtain such performance, through the criteria "Total time used in preventive maintenance" and "spare parts costs". In this way, the criticality evaluation allows highlighting equipment with a high availability due to a high expenditure on preventive maintenance and spare parts. To Muchiri et al. [34], maintenance management has to make conscious decisions to reduce the impact that equipment failures has, such as equipment downtime, quality problems, speed losses, safety hazards or environmental pollution. According to this, the defined criteria involve indicators or measures that translate the availability (or downtime) of the equipment (MTBF and MTTR) and the quality of manufactured products (Quality rate). Safety and environmental pollution are not considered since these adverse effects should be addressed without delay.

Furthermore, the method is based on the indicators that are more commonly used by maintenance management departments, facilitating its understanding as well as its implementation. 


\section{Conclusions and future work}

In a highly competitive business such as the automotive industry, preventive maintenance plans for manufacturing equipment are defined based on the manufacturer's recommendations and then updated based on experience. On a daily basis, given the tasks assigned to the maintenance department and the limited human resources, priorities must be defined and they are defined instinctively if no other methods have been adopted. In the medium and long term, equipment with worst performance are analyzed in order to adjust the preventive maintenance tasks and frequencies or to implement other measures to improve reliability and maintainability or to reduce costs. Once again, due to limited resources and time, a priority must be assigned to maximize the impact of the adopted measures.

Process automation helps companies to accomplish competitive goals. Equipment and tasks prioritization used in a CMMS can contribute to automate the process and give intelligence to the system, identifying dynamically and in real time the maintenance tasks that have to be performed first and the worst-performing equipment. With this automation, a significant impact on maintenance efficiency can be achieved. Maintenance coordinators or managers will have more time to support technicians instead of spending it at deciding which machines should be fixed or improved at each moment. Moreover, decisions are taken based on updated data and in a systematic manner. However, the use of these methods is only possible with interconnected systems. Therefore, their application becomes possible in the new manufacturing era, Industry 4.0.

This paper proposes two methods, a maintenance task ordering method and an equipment performance ranking method, based on criticality analysis, to support maintenance scheduling and improvement of manufacturing equipment of an automotive company. Since criticality assessment of tasks is based on the failure impact on operational performance and quality, the implementation of the priorities defined by the task ordering method will allow improving productivity. Moreover, the equipment performance ranking method can be a useful tool for continuous improvement in maintenance and productivity by monitoring equipment performance or to support the implementation of advanced technology. Based on this ranking, improvement teams can focus on the worst-performing machines. This proposed method has also the advantage of using data or indicators that are usually monitored by maintenance departments. The lack of quality of data may affect the results. Hence, in addition to choosing a suitable time interval to estimate the indicators, it is also necessary to assure that the records are complete and accurate.

The proposed methods are oriented to manufacturing plants in which equipment has safety systems to avoid accidents, during operation and when equipment functional failures occur. Thus, impact on safety and on environment is not considered either for tasks prioritization or for worst-performing equipment identification. The preventive tasks associated with failures of safety systems, such as inspections, and with failures with impact on environment should be performed without delays as well as necessary improvements for their avoidance.

Future work includes the development of an application of these methods to be included in the CMMS of the automotive company together with a scheduling algorithm to assign preventive maintenance tasks to technicians, taking into account tasks priorities and available periods.

\section{Funding}

This research is sponsored by the Portugal Incentive System for Research and Technological Development. Project in co-promotion no ${ }^{0} 002814 / 2015$ (iFACTORY 2015-2018) and has been partially supported by COMPETE: POCI-01- 0145-FEDER-007043 and FCT - Fundação para a Ciência e Tecnologia within the Project Scope: UID/CEC/00319/2013.

\section{References}

[1] Fernandez, O., Labib, A. W., Walmsley, R. and Petty, D. J. (2003), "A decision support maintenance management system: Development and implementation," International Journal of Quality \& Reliability Management, Vol. 20 No. 8, pp. 965-979.

[2] Ab-samat, H., Jeikumar, L. N., Basri, E. I., Harun, N. A and Kamaruddin, S. (2012), "Effective Preventive Maintenance Scheduling: A Case Study," in Proceedings of the 2012 International Conference on Industrial Engineering and Operations Management, Istanbul, pp. 1249-1257.

[3] Xiao, L., Song, S., Chen, X. and Coit, D. W. (2016), "Joint optimization of production scheduling and machine group preventive maintenance," Reliability Engineering and System Safety, Vol. 146, pp. 68-78.

[4] Manzini, R., Accorsi, R., Cennerazzo, T., Ferrari, E. and Maranesi, F. (2015), "The scheduling of maintenance. A resource-constraints mixed integer linear programming model," Computers \& Industrial Engineering, Vol. 87, pp. $561-568$.

[5] Hijes, F. and Cartagena, J. (2006), "Maintenance strategy based on a multicriterion classification of equipments," Reliability Engineering \& System Safety, Vol. 91, No. 4, pp. 444-451.

[6] Khanlari, A., Mohammadi , K., Sohrabi, B. (2008), "Prioritizing equipments for preventive maintenance (PM) activities using fuzzy rules," Computers and Industrial Engineering, Vol. 54, pp. 169-184.

[7] Stadnicka, D., Antosz, K. and Ratnayake, R. M. C. (2014), "Development of an empirical formula for machine 
classification: Prioritization of maintenance tasks," Safety Science, Vol. 63, pp. 34-41.

[8] Rastegari, A. and Mobin, M. (2016), "Maintenance decision making, supported by computerized maintenance management system," In 2016 Annual Reliability and Maintainability Symposium (RAMS), IEEE, pp.1-8.

[9] Guo, Y.-Z. and Dong, J. (1997), "The application of fuzzy clustering analysis in process equipment importance classification," International Journal of Pressure Vessels and Piping, Vol. 71, pp. 175-179.

[10] Jaderi, F., Sa’idi, E., Anvaripour, B. and Nabhani, N. (2012), "Criticality analysis for assets priority setting of Abadan Oil Refinery using AHP and Delphi Techniques," International Journal of Engineering and Innovative Technology, Vol. 2 No. 6, pp. 48-53.

[11] Azadeh, A., Ghaderi, S.F. , Ebrahimipour, V. (2007), "An integrated PCA DEA framework for assessment and ranking of manufacturing systems based on equipment performance," Engineering Computations, Vol. 24, No. 4, pp.347-372.

[12] Taghipour, S., Banjevic, D. and Jardine, A. (2010), "Prioritization of medical equipment for maintenance decisions," Journal of the Operational Research Society, pp.1-22.

[13] Campbell, J. D. and Jardine, A. (2001), Maintenance Excellence: Optimizing Equipment Life-Cycle Decisions, CRC Press, New York.

[14] Bevilacqua, M. and Braglia, M. (2000), "The analytic hierarchy process applied to maintenance strategy selection," Reliability Engineering \& System Safety, Vol. 70 No. 1, pp. 71-83.

[15] Labib, A. W. (2004), "A decision analysis model for maintenance policy selection using a CMMS," Journal of Quality in Maintenance Engineering, Vol. 10, No. 3, pp. 191-202.

[16] Shahin, A. and Attarpour, M. R. (2011), "Developing decision making grid for maintenance policy making based on estimated range of overall equipment effectiveness," Modern Applied Science, Vol. 5 No. 6, pp. 86-97.

[17] Velasquez, M. and Hester, P. T. (2013), "An Analysis of Multi-Criteria Decision Making Methods," International Journal of Operational Research, Vol. 10, No. 2, pp. 56-66.

[18] Li, L., Ni, J. (2009), "Short-term decision support system for maintenance task prioritization," International Journal of Production Economics, Vol. 121, pp. 195-202.

[19] Saleh, N., Sharawi, A., Elwahed, M., Petti, A., Puppato, D., and Balestra, G. (2015), "Preventive maintenance prioritization index of medical equipment using quality function deployment," IEEE Journal of Biomedical and Health Informatics, Vol. 19, No. 3, pp. 1029-1035.

[20] Singh, R. K. and Kulkarni, M. (2013), "Criticality analysis of power-plant equipments using the Analytic Hierarchy Process," International Journal of Industrial Engineering \& Technology, Vol. 3, No. 4, pp. 1-14.

[21] Qi, H.S., Alzaabi, R.N., Wood, A.S. and Jani, M. (2013), "A fuzzy criticality assessment system of process equipment for optimised maintenance management," International Journal of Computer Integrated Manufacturing, Vol. 28, No. 1, pp. 112-125.

[22] Jagtap, H. P. and Bewoor, A. K. (2017), "Use of Analytic Hierarchy Process methodology for criticality Analysis of thermal Power plant equipment," in Materials Today: proceedings, Vol. 4, pp 1927-1936.

[23] Márquez, A. C., León, P. M., Fernández,J.F. G., Márquez, C. P. and Campos, M. L. (2009), "The maintenance management framework: A practical view to maintenance management," Journal of Quality in Maintenance Engineering, Vol. 15, No. 2, pp.167-178.
[24] Guo, L., Gao, J., Yang, J. and Kang, J. (2009), “Criticality evaluation of petrochemical equipment based on fuzzy comprehensive evaluation and a BP neural network," Journal of Loss Prevention in the Process Industries, Vol. 22 No. 4, pp. 469-476.

[25] Faisall, M. and Sharawi, A, (2015), "Prioritize Medical Equipment Replacement Using Analytical Hierarchy Process," IOSR Journal of Electrical and Electronics Engineering, Vol. 10, No. 3, pp. 55-63.

[26] Peeters, J., Basten, R. and Ting, T. (2018), "Improving failure analysis efficiency by combining FTA and FMEA in a recursive manner," Reliability Engineering \& System Safety, Vol. 172, pp. 36-44.

[27] Roda, I., Macchi, M., Fumagalli, L., Viveros, P. (2014), "A review of multi-criteria classification of spare parts: From literature analysis to industrial evidences," Journal of Manufacturing Technology Management, Vol. 25, No. 4, pp. 528-549.

[28] Triantaphyllou, E. and Mann, S. H. (1995), "Using the Analytic Hierarchy Process for Decision Making in Engineering Applications: Some Challenges," International Journal of Industrial Engineering: Theory, Applications and Practice, Vol. 2, No. 1, pp. 35-44.

[29] Saaty, T. L. (2008), "Decision making with the analytic hierarchy process," International Journal of Services Sciences, Vol. 1 No. 1, pp. 83-98.

[30] Gass, S. I. and Rapcsák, T. (2004), "Singular value decomposition in AHP," European Journal of Operational Research, Vol. 154 No. 3, pp. 573-584.

[31] Subramanian, N. and Ramanathan, R. (2012), "A review of applications of Analytic Hierarchy Process in operations management," International Journal of Production Economics, Vol. 138, No. 2, pp. 215-241.

[32] Ahmad, R and Kamaruddin, S. (2012), "An overview of time-based and condition-based maintenance in industrial application," Computers \& Industrial Engineering, Vol. 63, No. 1, pp. 135-149.

[33] Saaty, T. L. (1980), The Analytic Hierarchy Process, Mc Graw-Hill, New York.

[34] Muchiri, P., Pintelon, L., Gelders, L and Martin, H. (2011), Development of maintenance function performance measurement framework and indicators, International Journal of Production Economics, Vol. 131, No. 1, pp. 295-302. 